Review Article

\title{
Posttraumatic Stress and Posttraumatic Stress Disorder after Termination of Pregnancy and Reproductive Loss: A Systematic Review
}

\author{
Viltè Daugirdaitè, ${ }^{1}$ Olga van den Akker, ${ }^{2}$ and Satvinder Purewal ${ }^{3}$ \\ ${ }^{1}$ Department of General Psychology, Philosophy Faculty, Vilnius University, Universiteto 9/1, Vilnius, LT-01513, Lithuania \\ ${ }^{2}$ Department of Psychology, Middlesex University, The Burroughs, Hendon, London NW4 4BT, UK \\ ${ }^{3}$ Institute of Psychology, University of Wolverhampton, Wulfruna Street, Wolverhampton WV1 1LY, UK \\ Correspondence should be addressed to Olga van den Akker; o.vandenakker@mdx.ac.uk
}

Received 14 July 2014; Accepted 20 January 2015

Academic Editor: Gian Carlo Di Renzo

Copyright ( 2015 Vilte Daugirdaite et al. This is an open access article distributed under the Creative Commons Attribution License, which permits unrestricted use, distribution, and reproduction in any medium, provided the original work is properly cited.

Objective. The aims of this systematic review were to integrate the research on posttraumatic stress (PTS) and posttraumatic stress disorder (PTSD) after termination of pregnancy (TOP), miscarriage, perinatal death, stillbirth, neonatal death, and failed in vitro fertilisation (IVF). Methods. Electronic databases (AMED, British Nursing Index, CINAHL, MEDLINE, SPORTDiscus, PsycINFO, PubMEd, ScienceDirect) were searched for articles using PRISMA guidelines. Results. Data from 48 studies were included. Quality of the research was generally good. PTS/PTSD has been investigated in TOP and miscarriage more than perinatal loss, stillbirth, and neonatal death. In all reproductive losses and TOPs, the prevalence of PTS was greater than PTSD, both decreased over time, and longer gestational age is associated with higher levels of PTS/PTSD. Women have generally reported more PTS or PTSD than men. Sociodemographic characteristics (e.g., younger age, lower education, and history of previous traumas or mental health problems) and psychsocial factors influence PTS and PTSD after TOP and reproductive loss. Conclusions. This systematic review is the first to investigate PTS/PTSD after reproductive loss. Patients with advanced pregnancies, a history of previous traumas, mental health problems, and adverse psychosocial profiles should be considered as high risk for developing PTS or PTSD following reproductive loss.

\section{Introduction}

Posttraumatic stress (PTS) and posttraumatic stress disorder (PTSD) after reproductive loss have not been well recognised, despite the growing documentation of adverse psychological states associated with reproductive losses. Our focus is on PTS and PTSD but did not include acute stress disorder (ASD) because ASD is a separate disorder diagnosed only in the first month following the traumatic event. Although the classification of TOP and reproductive loss varies from country to country [1], TOP broadly refers to the termination of a clinical pregnancy and miscarriage to the spontaneous loss of a clinical pregnancy before 20 completed weeks of gestation. Perinatal death, on the other hand, refers to a fetal or neonatal death after $20+$ weeks during pregnancy and childbirth or up to 7 days after birth, whereas stillbirth denotes the death of a (20+ weeks of gestational age) baby before the complete expulsion/extraction from its mother. A neonatal death is said to have occurred when a live born baby dies within 28 days of birth [2]. Failed in vitro fertilisation (IVF) is also considered by some infertile couples as a reproductive loss [3], with some women reporting grief, sadness, and distress with IVF failures $[4,5]$ and, for those who do become pregnant, a more intense protective attachment to their fetus [6]. PTS and PTSD can evolve after any of these reproductive losses [7-10].

Further, TOP is different from other reproductive losses as it involves a "choice" of the woman to terminate a pregnancy or not, but the event itself is a stressful situation and can become traumatic for some women [11]. It is also important to separate nonmedical TOP (which is usually requested for social reasons) from medical TOP, which is usually requested 
when there is evidence of foetal abnormality which could lead to giving birth to a baby unlikely to survive long, or when the difficulties of rearing an affected child are perceived as too great to be acceptable to the couple [12]. The differences between medical and nonmedical TOP are further highlighted in societal/cultural acceptance and legal status. For instance, many African or Latin American countries will not allow nonmedical TOPs [13], although the World Health Organisation [14] reported that highly restrictive abortion laws did not lower TOP rates, stigmatising this illegal practice further. Specifically, the abortion rate is 29 per 1,000 women of childbearing age in Africa (where TOP is illegal under most circumstances in most countries) compared with 12 per 1000 in Western Europe (where abortion is permitted in many countries). Nonmedical TOP may not be recognized as a traumatic event by some women because they do not want the baby [15]. However, some of these women subsequently regret having had the abortion and can experience it as trauma [16]. Not all women experiencing a nonmedical TOP will experience posttraumatic consequences [17] but that is also true for medical TOP and all other reproductive losses. Nonetheless the psychological impact of nonmedical and medical TOP may be different, but the extent to which they differ needs further investigation.

Although mental health promotion following reproductive loss is underinvestigated [18], PTSD after childbirth and pregnancy loss has been distinguished from postnatal depression and complicated grief $[19,20]$. Studies which have investigated PTS and/or PTSD following reproductive loss and TOP have reported mixed results $[13,21]$. For example, high levels of PTSD following nonmedical TOP have been reported by some [22] but not all previous research [23]. At present, there is no systematically pooled research evidence on PTS and its disorder after TOP and reproductive loss. The rationale for this systematic review is therefore to reconcile previous research and deliver the first review that integrates research on PTS and PTSD after all reproductive losses (TOP, miscarriage, perinatal loss, stillbirth, neonatal death, and failed IVF) for women and men and investigate the prevalence and factors influencing the development of PTS/PTSD after each reproductive loss. TOP and other reproductive losses were included to provide a comprehensive account of the research literature, including a quality assessment and a direct examination of the differences between TOPS and reproductive losses in relation to PTS and PTSD.

\section{Methods}

2.1. Search Strategy. The electronic databases (AMED, British Nursing Index, CINAHL, MEDLINE, SPORTDiscus, PsycINFO, PubMEd, and ScienceDirect) were searched for relevant articles and followed the PRISMA guidelines [24]. No restriction for time of publication was set and only English language peer-reviewed publications were included. The search was last updated in May 2012. In PubMEd, the following key words were used in title/abstract search: "miscarriage" or "stillbirth" or "abortion" or "neonatal death" or "perinatal loss" or "failed IVF" or "failed in vitro fertilization" or "failed in vitro fertilization" or "pregnancy loss" or "termination of pregnancy" and "trauma" or "stress" or "PTSD" or "posttraumatic stress," or "posttraumatic stress disorder."

2.2. Study Selection. All papers had to be published in peerreviewed journals, available in English and presenting original data. Studies were selected if they investigated PTSD/PTS associated with TOP and/or other reproductive losses (miscarriage, perinatal loss, stillbirth, neonatal death, and failed IVF). Quantitative studies were selected if they used standardised measurements of PTS/PTSD and qualitative studies were selected if they investigated the trauma of TOP and reproductive loss in the interviews. Studies had to use standard criteria for PTS/PTSD to be included. For PTS the reaction to traumatic events is characterised with involuntary repetition in thought, emotion, and behaviour of stress relevant contents. PTS is a marker of possibly developing the disorder, which depends on the intensity of these and other symptoms and require other conditions to become a disorder [25]. We did not include ASD in our systematic review because ASD does not necessarily lead to PTSD and is more time limited. Further, PTSD (PTS's disorder) is the development of characteristic symptoms following exposure to an extreme traumatic stressor. The characteristic symptoms resulting from the exposure to the extreme trauma include persistent reexperiencing of the traumatic event, persistent avoidance of stimuli associated with the trauma and numbing of general responsiveness, and persistent symptoms of increased arousal [26].

Studies which investigated existing PTS/PTSD as a risk factor for TOP or reproductive loss were excluded because the focus was on reproductive loss as a risk factor for PTS/PTSD. Further, data were collected on whether the studies included controlled for pre-TOP or prereproductive loss of mental health in their data analyses. Clinical case studies with no research agenda, books, correspondence letters, discussions, book reviews, product reviews, editorials, publisher's notes, and errata were excluded from the review. To avoid multiple publication bias [27] only one paper was selected from multiple publications and selection was based upon highest quality, followed by largest number of participants, highest number of reproductive losses, longest length of follow-up, and the paper with most reported outcome measurement data. Numbers included and reasons for exclusion are shown in Figure 1.

2.3. Data Abstraction. A data extraction sheet was used to collect relevant information. This included author's details, country of study, design, sample size, variables measured, results, quality of study evaluation. Data was extracted from relevant articles (VD) and cross-checked (OvdA and SP).

2.4. Screening and Quality Assessment. Quality assessment of articles which met the inclusion criteria was determined by VD using Cochrane criteria adapted by Green et al. [28]. These were independently checked by OvdA and SP, and disagreements were resolved following discussion; criteria were

(i) adequate sample size,

(ii) representative of study population, 


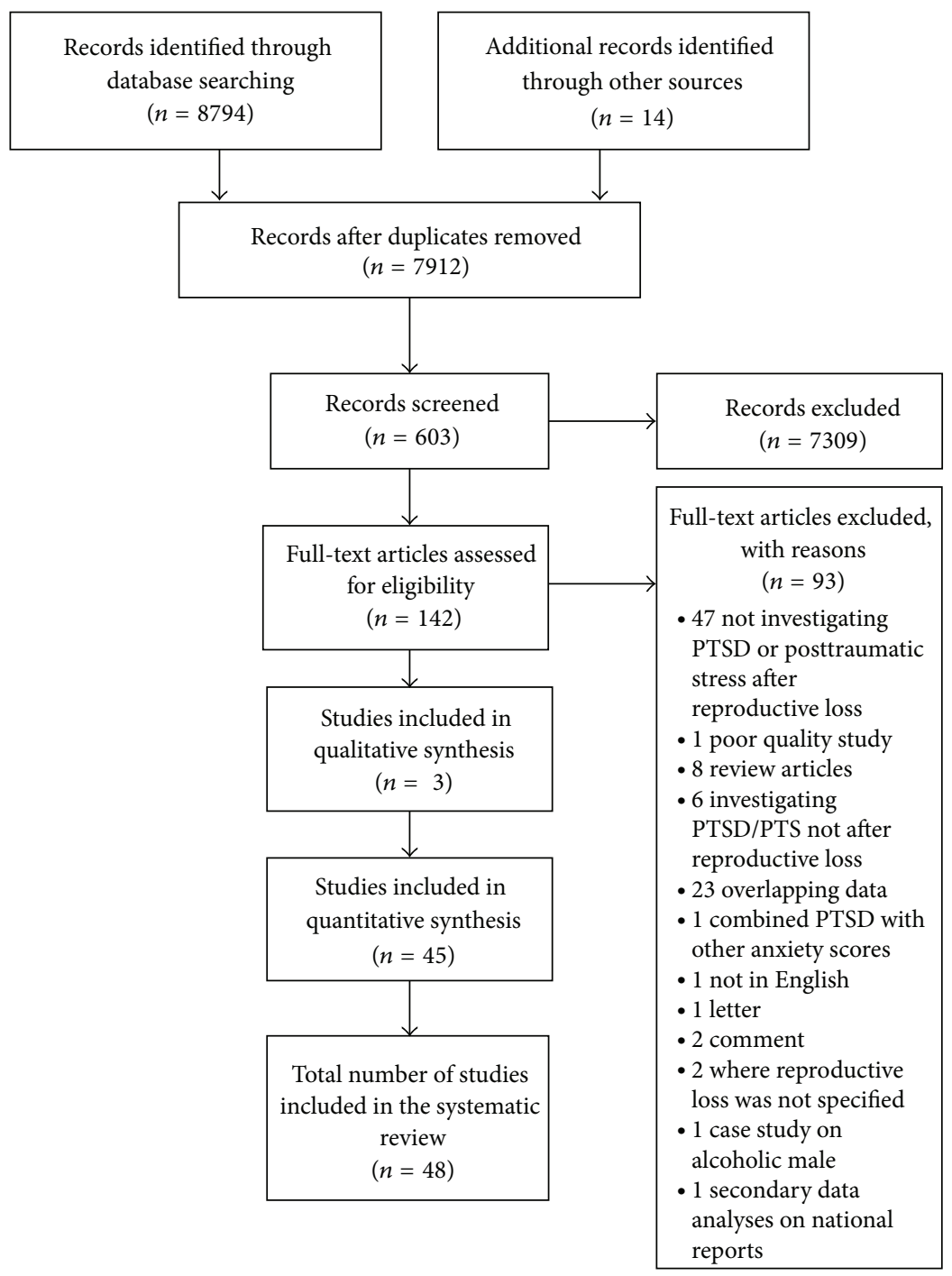

FIGURE 1: PRISMA flow diagram.

(iii) high response rate,

(iv) using mostly validated measures,

(v) mostly appropriate timing of measures,

(vi) measures consistent with aims,

(vii) conclusions consistent with results,

(viii) methodology is clear,

(ix) analysis is clear.

\section{Results}

As can be seen from the PRISMA flow chart (Figure 1), the search of the databases yielded 8794 titles of records and 14 records from searching reference lists. After duplicates were removed, 7912 records were left. Titles were reviewed and 7309 articles did not meet the inclusion criteria. Of the 603 abstracts reviewed, 461 failed to meet the inclusion criteria. Finally full texts of the remaining 142 papers were read and
48 studies were identified as meeting the inclusion criteria. As shown in Figure 1, 23 studies [29-51] were excluded for reporting overlapping data and 12 studies [22, 23, 52-61] from multiple reports were included. Further, one eligible study was removed [62] over serious reported methodological and statistical concerns over the study [63].

3.1. Study Characteristics. The study characteristics of the 48 included articles are shown in Tables 1-4; Table 1 includes TOP, Table 2 miscarriage, Table 3 perinatal loss, and Table 4 stillbirths. Each table is separated in two parts ( $a$ and b) with section a representing studies which have investigated the type of reproductive loss alone and section (b) presenting studies which have investigated that type with other losses.

As shown in Table 1, 20 studies examined PTS/PTSD after TOP (Table 1(a)); seven examined TOP with miscarriage, perinatal loss, or neonatal death (Table 1(b)). Eighteen reported nonmedical TOP $[22,23,53,61,62,64-76]$, one nonmedical TOP and medical TOP [77]; eight were medical TOP 
TABLE 1: Characteristics of included studies for TOP (a) and TOP with miscarriage/perinatal loss/neonatal death (b).

$\begin{array}{llll}\begin{array}{l}\text { Authors, year, country, and author } \\ \text { listing in reference list }\end{array} \text { Methods } & \begin{array}{l}\text { Reproductive loss, Participants, } \\ \text { and control for Prereproductive } \\ \text { loss }\end{array} & \begin{array}{c}\text { Outcomes } \\ \text { measurements }\end{array}\end{array} \quad$ Quality

(a) Termination of pregnancy (TOP). Numbers of participants are women, men, or couples and are noted separately.

(1) Allanson (2007), Australia [64]

P, L Prereproductive loss mental

health parameters statistically not controlled

(2) Cohen and Roth (1984), USA [65] P

Nonmedical TOP $n=55$

Prereproductive loss mental

health parameters statistically controlled

(3) Coyle et al. (2010) USA [22]

Note. This study was chosen over [32]; it

had larger number of reported

participants.

(4) Davies et al. (2005), UK [79]

$\mathrm{P}$

Nonmedical TOP 374 women; 198 men

$\mathrm{R}$ Prereproductive loss mental health parameters statistically controlled

\section{Medical TOP 30;}

Prereproductive loss mental health parameters statistically not controlled

Nonmedical TOP 67

(5) van Emmerik et al. (2008), The Netherlands [66]

P Prereproductive loss mental health parameters statistically not controlled

Nonmedical TOP 219

(6) Hemmerling et al. (2005), Germany [67]

P, I Prereproductive loss mental

health parameters statistically not controlled

Nonmedical TOP 122

(7) Kelly et al. UK (2010) [68]

P, I Prereproductive loss mental

health parameters statistically controlled

(8) Kersting et al. (2009), Germany [58]

Note. This study was chosen over [41] because of a higher quality rating and [42] because it reports more participants and relevant data.

(9) Korenromp et al. (2005a), The Netherlands [59]

Note. This study was chosen over [43]

because of higher quality rating.

(10) Korenromp et al. (2007), The Netherlands [60]

Note. This study was chosen over [44]

because of a larger sample.

(11) Layer et al. (2004), USA [69]

P, I Prereproductive loss mental

health parameters statistically

62 medical TOP; 43 preterm

birth; 65 spontaneous delivery

P, L Prereproductive loss mental

health parameters statistically

not controlled

\section{Medical TOP 196}

R Prereproductive loss mental

health parameters statistically not controlled

Medical TOP 217 women; 169

men

P, L Prereproductive loss mental

health parameters statistically not controlled

not controlled

Nonmedical TOP 35

not controlled

(12) Major et al. (2000), USA [23]

Notes. This study was chosen over [45]

because it reported more data.

\section{Nonmedical TOP 442}

P, L

Prereproductive loss mental

health parameters statistically not controlled for PTSD
IES

5

IES

5

PTSD

Checklist-Civilian

Version

IES

IES

7

IES

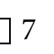

IES

5
5

6

5


TABLE 1: Continued.

Authors, year, country, and author listing in reference list
(13) Mufel et al. (2002), Belarus, USA

[61]

Note. This study was chosen over [475 ]

because of a higher quality rating.

(14) Pope et al. (2001), USA [70]

$\mathrm{P}$

Methods

Reproductive loss, Participants,

and control for Prereproductive loss

Nonmedical TOP 150

$\mathrm{R} \quad$ Prereproductive loss mental

health parameters statistically not controlled

Nonmedical TOP 96

Prereproductive loss mental

health parameters statistically not controlled for PTS

Nonmedical TOP 70

(15) Rousset et al. (2012), France [71]

P, I

Prereproductive loss mental

health parameters statistically not controlled

Nonmedical TOP 331 Russian women; 217 American women

(16) Rue et al. (2004), USA [72]

$\mathrm{R}$

Prereproductive loss mental health parameters statistically not controlled

Nonmedical TOP 275

(17) Slade et al. (1998), UK [73]

P, I Prereproductive loss mental

health parameters statistically not controlled for PTS

Nonmedical TOP 151

(18) Suliman et al. (2007), South Africa

[74]

P, I Prereproductive loss mental

health parameters statistically controlled

(19) Trybulski (2006), USA [75]

(20) Walters and Oakley (2002), UK [76]
Q

CS

Nonmedical TOP 16

Nonmedical TOP 1

Prereproductive loss mental health parameters statistically not controlled
Outcomes

measurements

Quality
IES-R

IES

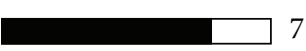

Institute of Pregnancy

Loss questionnaireincluding criteria for PTSD on DSM-IV
IES-R

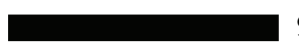

IES

Clinician-

administered PTSD

scale (CAPS-I)

Qualitative interview.
$\begin{aligned} & \text { The Post-Traumatic } \\ & \text { Stress Diagnostic } \\ & \text { Scale }\end{aligned}$

(b) TOP and miscarriage/perinatal loss/neonatal death

(21) Broen et al. (2005b), Norway [53]

Note. This study was chosen over [31]; it

has a higher quality rating/longer

follow-up time [30].
40 miscarriages; 80 Nonmedical

TOP

P, L Prereproductive loss mental

health parameters statistically controlled

Nonmedical TOP (30); medical

TOP (10); miscarriage (10).

(22) Canário et al. (2011), Portugal [77] P Prereproductive loss mental health parameters statistically not controlled

7 medical TOP, 8 miscarriages

Prereproductive loss mental

health parameters statistically not controlled

(23) Cowchock et al. (2011), USA [78] P

Q 2 medical TOP; 5 miscarriages

(24) Fernandez et al. (2011), Canada [80]

(25) Hamama et al. (2010), USA [55]

Note. This study was chosen over [46]

because of more relevant PTSD data.
405 prior pregnancies; 221 prior nonmedical TOP; 206

P miscarriages; 22 reported both Prereproductive loss mental health parameters statistically not controlled
Qualitative interviews

IES

IES-R 6

\author{
Interview (National \\ Women's Study PTSD \\ Module \\ (NWS-PTSD)).
}


TABle 1: Continued.

\begin{tabular}{llll}
\hline $\begin{array}{l}\text { Authors, year, country, and author } \\
\text { listing in reference list }\end{array}$ & Methods $\begin{array}{l}\text { Reproductive loss, Participants, } \\
\text { and control for Prereproductive } \\
\text { loss }\end{array}$ & $\begin{array}{c}\text { Outcomes } \\
\text { measurements }\end{array}$ \\
\hline (26) Kroth et al. (2004), USA [81] & $\mathrm{R} \quad \begin{array}{l}\text { Medical TOP, miscarriage, } \\
\text { perinatal loss, and neonatal death } \\
37 \text { women } \\
\text { Prereproductive loss mental } \\
\text { health parameters statistically } \\
\text { not controlled }\end{array}$ & IES \\
\hline (27) Salvesen et al. (1997), Norway [82] & $\mathrm{P} \quad \begin{array}{l}\text { 24 medical TOP, 29 perinatal } \\
\text { losses/neonatal deaths } \\
\text { Prereproductive loss mental } \\
\text { health parameters statistically } \\
\text { not controlled }\end{array}$ & IES \\
\hline
\end{tabular}

Notes: $\mathrm{CS}=$ case study; $\mathrm{I}=$ intervention design; $\mathrm{IES}=$ Impact of Event Scale; $\mathrm{IES}-\mathrm{R}=$ Revised $\mathrm{L}=$ longitudinal; $\mathrm{P}=$ prospective; $\mathrm{Q}=$ qualitative; $\mathrm{R}=$ retrospective.

[58-60, 77-82]. Table 2 shows 10 studies examining PTS/ PTSD after miscarriage (Table 2(a) [54, 83-91]), five miscarriages with perinatal loss, stillbirth, and neonatal death (Table 2(b) [92-96]). Table 3 shows that one study examined PTS/PTSD after perinatal loss (Table 3(a) [52]) and two studies examined perinatal loss with neonatal death (Table 3(b) [57, 97]). Finally, Table 4 reports two studies investigating PTS/PTSD after stillbirth (Table 4(a) $[56,98]$ ) and one stillbirth with neonatal death (Table 4(b) [99]). No study investigated PTS or PTSD after failed IVF.

Some studies did not distinguish between reproductive types in their data analyses (e.g., [57, 81, 82, 93, 94, 99]) and gestational ages were not reported for $n=10 / 48$ studies. The majority of studies used prospective designs, and sample sizes were generally small. PTS was consistently measured ( $n=33 / 49$ ) with the Impact of Event Scale (IES), the Revised IES (IES-R), or Perinatal Event Scale-adapted from Impact of Events Scale. The IES includes two subscales, intrusion and avoidance, and the IES-R also includes hyperarousal. Diagnoses of PTSD were done using diagnostic interviews $(n=4)$ or questionnaires $(n=10)$. Timing of outcome measurements or time since reproductive loss ranged from immediately after $(n=7 / 48)$ up to one year postloss $(n=$ 25/48). Most quantitative studies did not control for pre-TOP or prereproductive loss of mental health parameters in their statistical analyses (33/48). Data from 6379 women and men who experienced TOP or reproductive loss and 573 controls were included in the review. The majority of studies were conducted either in Europe $(n=24 / 48)$ or the USA $(n=18 / 48)$, most participants were white, and postloss support in Western countries is likely to be better resourced than in developing countries [8]. The quality of the studies was mostly good. See the Appendix more detailed information on each study.

\subsection{Prevalence of PTS and PTSD after TOP and Reproductive} Loss. Where more than one type of reproductive loss is reported ( $n=16 / 48$ ), studies are only discussed with the TOP or reproductive loss they are presented with, as demonstrated on Tables 1-4. Further, only observational studies are presented here; intervention studies (i.e., therapy or TOP procedure type, nonsurgical versus surgical) are discussed later.
3.2.1. Nonmedical TOP. For nonmedical TOP $12.6 \%$ met PTSD criteria, similar to rates for women with a prior miscarriage (12.5\%) but higher than women without prior reproductive loss (6.3\%) [55]. Data from online surveys estimated much higher rates of PTSD (54.9\% women and $43.4 \%$ of men) up to 15 years after the TOP [22]. However, recruitment was through online resources including abortion support groups suggesting that the sample may not be representative.

Studies from abortion clinics reported moderate levels (19.4\%) of PTS at two months post-TOP decreasing over time [66], and few cases of PTSD $(1 \% n=441)$ were reported at two years' post-TOP [23]. Adolescents also report low scores on intrusion four weeks post-TOP (719), and one study reported that PTS was high before TOP but decreased within 5 hours postoperation [65] or reported initially high PTS reducing to "negligible levels of distress" at 3 months postTOP [64].

No differences between men and women or at 1 and 6 months were found for nonmedical TOP or medical TOP and miscarriage [77]. Before nonmedical TOP, women were less likely to report PTS intrusion than women before miscarriage $(n=40)$ and less PTS avoidance at 2 years and 5 years postTOP compared to post miscarriage [53]. American women $(14.3 \%)$ are more likely to meet full diagnostic criteria for PTSD compared to Russian women (0.9\%) [72].

3.2.2. Medical TOP. Following medical TOP, reports of PTS are high $(64.5 \%)$ [58], with PTS reducing from $67 \%$ to $41 \%$ at 12 months. Second trimester medical TOP is more likely to result in PTS at six weeks than first trimester medical TOP but this difference disappeared at 12 months [79]. In a retrospective study of medical TOP, 33\% continued to report PTS up to a mean time of 4 years since the loss [59]. Women (44\%) report higher rates of PTS than men (21.6\%) [60]; pregnant women who had a previous medical TOP are less likely to report PTS than pregnant women with previous miscarriage [78] and significantly lower PTS is reported after medical TOP than perinatal/neonatal death [82].

3.2.3. Miscarriage. One study found that PTSD is infrequently reported three months after miscarriage [90]. Of 
TABle 2: Characteristics of included studies for miscarriage (a) and miscarriage with perinatal loss/stillbirth/neonatal death (b).

\begin{tabular}{|c|c|c|c|c|}
\hline $\begin{array}{l}\text { Authors year, country, and author } \\
\text { listing in reference list }\end{array}$ & Methods & $\begin{array}{l}\text { Reproductive loss, Participants, } \\
\text { and control for Prereproductive } \\
\text { loss }\end{array}$ & $\begin{array}{l}\text { Outcomes } \\
\text { measurements }\end{array}$ & Quality \\
\hline \multicolumn{5}{|c|}{ (a) Characteristics of included studies for miscarriage } \\
\hline (28) Alderman et al. (1998), USA [83] & $\mathrm{R}$ & $\begin{array}{l}\text { Miscarriage } 19 \text { couples } \\
\text { Prereproductive loss mental } \\
\text { health parameters statistically } \\
\text { not controlled }\end{array}$ & IES & \\
\hline (29) Bowles et al. (2006), USA [84] & $\mathrm{P}, \mathrm{L}$ & $\begin{array}{l}\text { Miscarriage } 25 \\
\text { Prereproductive loss mental } \\
\text { health parameters statistically } \\
\text { not controlled }\end{array}$ & $\begin{array}{l}\text { Posttraumatic Stress } \\
\text { Diagnostic Scale }\end{array}$ & \\
\hline $\begin{array}{l}\text { (30) Engelhard et al. (2003a), The } \\
\text { Netherlands [54] } \\
\text { Note. This study was chosen over } \\
\text { [33-37] because of the largest number } \\
\text { of reported participants/reported the }\end{array}$ & $\mathrm{P}, \mathrm{L}$ & $\begin{array}{l}\text { Miscarriage } 118 \\
\text { Prereproductive loss mental } \\
\text { health parameters statistically } \\
\text { controlled }\end{array}$ & $\begin{array}{l}\text { Posttraumatic } \\
\text { Symptom Scale }\end{array}$ & \\
\hline
\end{tabular}

most data.

(31) Johnson and Puddifoot (1996), UK
[85]

\section{P Preproductive loss mental}

Prereproductive loss mental
health parameters statistically not controlled

\section{Miscarriage 39}

(32) Lee et al. (1996), UK [86]

P, I Prereproductive loss mental health parameters statistically controlled

\section{Miscarriage 37}

(33) Rowsell et al. (2001), UK [87]

P, I Prereproductive loss mental health parameters statistically not controlled

Miscarriage 134

(34) Séjourné et al. (2010), France [88]

P, I Prereproductive loss mental

health parameters statistically not controlled for PTS

Miscarriage 30 women and 30 men

(35) Serrano and Lima (2006), Portugal [89]

Prereproductive loss mental

health parameters statistically

not controlled

\section{Miscarriage 161}

(36) Sham et al. (2010), Hong Kong [90]

\section{P, L Prereproductive loss mental}

health parameters statistically

Structural clinical controlled

Miscarriage 40

(37) Walker and Davidson (2001), UK [91]

\section{P Prereproductive loss mental}

health parameters statistically controlled interview for DSM-IV

IES
IES

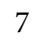

IES

(b) Miscarriage and perinatal/stillbirth/neonatal death

Miscarriage and Perinatal loss 40

expectant couples

(38) Armstrong (2004), USA [92]

P Prereproductive loss mental

health parameters statistically not controlled

Miscarriage; perinatal loss/neonatal loss/other complications 76 pregnant

(39) Forray et al. (2009), USA [93] women, of which 18 underwent interviews

Prereproductive loss mental

(Modified Clinical administered PTSD Scale (m-CAPS)) 
TABLe 2: Continued.

Authors year, country, and author listing in reference list

- Methods

(40) Jind (2001), Denmark [94]

$\mathrm{R}$

(41) Jind (2003), Denmark [95]

(42) O’leary (2005), USA [96]
Reproductive loss, Participants,

and control for Prereproductive loss

Miscarriage/perinatal, stillbirth, and neonatal death/infant loss 602 parents

Prereproductive loss mental health parameters statistically not controlled

Miscarriage, perinatal loss, stillbirth, and neonatal death/infant loss; 93 parents at the first measurement, 65 parents The Harvard Trauma at the second measurement Prereproductive loss mental health parameters statistically not controlled

Miscarriage, perinatal loss, stillbirth and infant loss; 12 expecting mothers and 9 expecting fathers
Qualitative

Interviews.
Outcomes

measurements

Quality

IES, Harvard trauma Questionnaire
Questionnaire

TABLE 3: Characteristics of included studies for perinatal loss (a) and perinatal loss with neonatal death (b).

\begin{tabular}{|c|c|c|c|c|}
\hline $\begin{array}{l}\text { Authors year, country, and author } \\
\text { listing in reference list }\end{array}$ & Methods & $\begin{array}{l}\text { Reproductive loss, Participants } \\
\text { and control for Prereproductive } \\
\text { loss }\end{array}$ & $\begin{array}{l}\text { Outcomes } \\
\text { measurements }\end{array}$ & Quality \\
\hline \multicolumn{5}{|c|}{ (a) Perinatal loss } \\
\hline $\begin{array}{l}\text { (43) Armstrong et al. (2009), USA [52] } \\
\text { Note. This study was chosen over } \\
\text { [29]because it had a higher quality } \\
\text { rating. }\end{array}$ & $\mathrm{P}, \mathrm{L}$ & $\begin{array}{l}\text { Perinatal loss } 36 \text { couples } \\
\text { Prereproductive loss mental } \\
\text { health parameters statistically } \\
\text { not controlled }\end{array}$ & IES & 7 \\
\hline \multicolumn{5}{|c|}{ (b) Perinatal loss and neonatal death } \\
\hline $\begin{array}{l}\text { (44) Hunfeld et al. (1993), Netherlands } \\
\text { [57] } \\
\text { Note. This study was chosen over } \\
\text { [39, 40] because of a higher quality } \\
\text { rating and [38] because of more relevant } \\
\text { PTSD data. }\end{array}$ & $\mathrm{P}, \mathrm{L}$ & $\begin{array}{l}\text { Perinatal loss and neonatal death; } \\
46 \\
\text { Prereproductive loss mental } \\
\text { health parameters statistically } \\
\text { not controlled }\end{array}$ & $\begin{array}{l}\text { Perinatal Event } \\
\text { Scale -adapted } \\
\text { from Impact of } \\
\text { Event Scale }\end{array}$ & 9 \\
\hline (45) Hutti et al. (2011), USA [97] & $\mathrm{P}, \mathrm{L}$ & $\begin{array}{l}\text { Perinatal loss and neonatal death; } \\
106 \text { women } \\
\text { Prereproductive loss mental } \\
\text { health parameters statistically } \\
\text { not controlled }\end{array}$ & IES & 7 \\
\hline
\end{tabular}

studies reporting PTS after miscarriage, a reduction is reported after 3 [91] to 4 months [54], although an increase in PTSD over time has also been reported [84]. Other reports find higher levels with $67.9 \%$ of pregnant women with prior miscarriage or perinatal loss meeting partial or full criteria for PTSD [93]. Similar high numbers (82\% PTS; 80\% PTSD) were reported in men and women after miscarriage, perinatal, stillbirth, or neonatal death/infant death three years previously [94]. However, data was not separated for reproductive loss type and the sample was recruited from a support group and may not be representative. Hospital samples record lower numbers (11\% with PTSD) which reduced still further $(2.8 \%)$ 4-12 months follow-up [95].

Women who experienced recurrent miscarriage were more likely to report intrusion [83] or intrusion and avoidance than their partners [89]. Pregnant women who had a previous miscarriage or perinatal loss scored high on avoidance and men scored high on intrusion with $88 \%$ of women and $90 \%$ of men meeting the cut-off for PTS [92], confirming other reports of clinical levels of PTS in men [85]. 
TABLE 4: Characteristics of included studies for stillbirth (a) and stillbirth with neonatal death (b).

\begin{tabular}{|c|c|c|c|c|c|}
\hline $\begin{array}{l}\text { Authors year, country, and author } \\
\text { listing in reference list }\end{array}$ & Methods & $\begin{array}{l}\text { Reproductive loss, Participants } \\
\text { and control for Prereproductive } \\
\text { loss }\end{array}$ & $\begin{array}{l}\text { Outcomes } \\
\text { measurements }\end{array}$ & Quality & \\
\hline \multicolumn{6}{|c|}{ (a) Stillbirth } \\
\hline (46) Cacciatore (2007), USA [98] & $\mathrm{R}$ & $\begin{array}{l}\text { Stillbirth } 47 \\
\text { Prereproductive loss mental } \\
\text { health parameters statistically } \\
\text { not controlled }\end{array}$ & IES-R & & 6 \\
\hline $\begin{array}{l}\text { (47) Hughes et al. (2002), UK [56] } \\
\text { Note. This study was chosen over } \\
\text { [48-51] because of the highest quality } \\
\text { rating/reported more participants/data. }\end{array}$ & $\mathrm{P}$ & $\begin{array}{l}65 \text { pregnant women, with prior } \\
\text { stillbirth, } 60 \text { controls } \\
\text { Prereproductive loss mental } \\
\text { health parameters statistically } \\
\text { controlled }\end{array}$ & PTSD-1 Interview & & \\
\hline \multicolumn{6}{|c|}{ (b) Stillbirth and neonatal death } \\
\hline $\begin{array}{l}\text { (48) Uren and Wastell (2002), } \\
\text { Australia [99] }\end{array}$ & $\mathrm{R}$ & $\begin{array}{l}\text { Stillbirth and neonatal loss; } 109 \\
\text { women } \\
\text { Prereproductive loss mental } \\
\text { health parameters statistically } \\
\text { not controlled }\end{array}$ & IES-R & 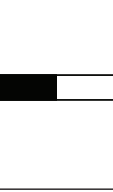 & 5 \\
\hline
\end{tabular}

3.2.4. Perinatal Loss. PTS is initially high [52, 97] and decreases to moderate levels 8 months postpartum in couples with a history of perinatal loss who subsequently had a healthy infant [52]. Specifically intrusion increased more in women and avoidance remained stable in both [52], or PTS remained high and unchanged from the first diagnosis to three months after delivery/death [57].

3.2.5. Stillbirth. One longitudinal study of 65 pregnant women who had a prior stillbirth reported $21 \%$ PTSD in the third trimester and $4 \%$ at one year after birth [56].

\subsection{Factors Influencing PTS and/or PTSD after TOP and Reproductive Loss}

3.3.1. Nonmedical TOP. Having a TOP predicted a diagnosis of PTSD and sociodemographic variables (younger age, poverty, poor education, poor housing, and race), history of sexual trauma, and illness or medical trauma are other risk factors independently predicting PTSD [55]. A history of sexual or medical trauma doubled the risk for PTSD [55], whereas harsh discipline as a child, adult rape, and physical or emotional abuse were associated with PTSD [72], and a history of major depression also predicted PTSD [23]. Peritraumatic dissociation and difficulties in describing feelings were significant predictors of PTS [66].

Relationship stability as a reason to continue the pregnancy is a strong predictor of intrusion symptoms [64]. Couple's disagreement towards having a TOP and inadequate before abortion counselling significantly predicted PTSD in women and men [22] and in women, knowing others who have not coped with TOP [64], attachment to the foetus, recognition of life, time since abortion, and increased maternal age predicted PTSD [61]. Higher levels of perceived quality in couple's relationship [77] and active coping influence short term PTS after nonmedical TOP [65]. Spiritual group therapy reduces PTS for women experiencing postTOP grief, although no control group was used [69] and hypnosis with psychological therapy successfully reduced symptoms of PTSD in a case study [76]. Recurrent thoughts continued to affect and traumatise women's lives up to 15 years post-TOP in a qualitative study [75].

Research considering type of TOP procedure reporting nonsurgical TOP predicts PTSD $[68,71]$, surgical TOP is associated with PTS [67], or no differences between nonsurgical or surgical TOP on PTS [72]. No differences between local anaesthesia and intravenous sedation in surgical TOP were reported either [74].

3.3.2. Medical TOP. PTS in women was also predicted by sociodemographic factors [79] (low education, younger maternal age, and advanced gestation) and low levels of partner support $[59,60]$, whereas, for men, being religious and doubt over decision predicted PTS [60]. PTS is also associated with perinatal grief, depression, and anxiety for pregnant women with prior medical TOP or miscarriage [78]. In women with medical TOP, miscarriage, stillbirth, and neonatal death, recruited through support groups, PTS was correlated with low levels of social support, perinatal grief, emotional pain, emotional expression, and, less strongly, dream frequency [81]. Depression had also been associated with high intrusion scores for women who experienced medical TOP and perinatal loss/neonatal death [82]. Difficult physical symptoms of miscarriage and TOP and having to make the decision to have a medical TOP were experienced as traumatic in a qualitative investigation [80].

3.3.3. Miscarriage. A diagnosis of acute stress disorder [84], peritraumatic dissociation, and neuroticism [54] leads to PTSD one to 4 months after loss. Unplanned pregnancies are significantly related to PTS [91]. Both men and women have clinical levels of PTS although sociodemographic variables 
and quality of relationship do not predict PTS for either [89]. However, for men, PTS was more likely to be associated with perinatal grief and older gestational age and viewing the ultrasound scan were significantly associated with PTS [85], whereas, for women, viewing scans and early warning signs for miscarriage were not associated with PTS [91]. Psychological therapy to reduce PTS is ineffective; it usually declines spontaneously over time [86-88].

Depression, and pregnancy related anxiety, but not prenatal attachment related to PTS in couples with prior miscarriage or perinatal loss [92]. Depression, anxiety, and poly substance disorders cooccurred for some women with full or partial PTSD diagnosis after miscarriage and other reproductive losses [93]. PTSD is also associated with feelings of doubt [94] and attribution of blame [95]. Ultrasound of the current pregnancy triggered flashbacks and symptoms of PTSD for some women with prior miscarriage, perinatal loss, stillbirth, and infant loss [96].

3.3.4. Perinatal Loss. Depression was significantly correlated with PTS during a current pregnancy and eight months following delivery for women and men with prior perinatal losses [52]. For women, anxiety was associated with PTS during pregnancy but, for men, anxiety was associated with PTS during and after delivery [52]. For pregnant women with a history of perinatal loss and neonatal death, intrusion was associated with an increase of women's healthcare use [97]. For women experiencing a neonatal death, those who delivered early were more likely to experience intrusion than women who delivered after 34 weeks [57].

3.3.5. Stillbirth. At one year postdelivery, seeing and holding the stillborn infant was significantly associated with PTSD in pregnant women with a previous history of stillbirth [56]. Attending support groups significantly predicted lower PTS [98]. Finally, in women who experienced a stillbirth or neonatal death, intrusion and hyperarousal predicted perinatal grief [99].

\section{Conclusion}

Systematic research evidence on the prevalence of PTS or PTSD associated with failed IVF is nonexistent, and few studies reported on PTS/PTSD following perinatal loss, neonatal death, or stillbirth, usually alongside other reproductive losses. There were more studies on PTS/PTSD after miscarriage and TOP for nonmedical and medical reasons. However, the research is inconsistent with regards to prevalence rates which depended on how participants were recruited. In some cases, no prevalence rates, reproductive loss type, or gestational age of the loss were recorded, reflecting the lack of research into the mental health of patients following reproductive loss [18].

Overall, this review has demonstrated that PTSD occurs after nonmedical and medical TOP, miscarriage, perinatal loss, and stillbirth, although it is much less commonly reported than PTS. Length of gestational age is associated with an increased likelihood for diagnosis of PTS or PTSD.
The percentage of PTS and its disorder is highest during the first weeks after TOP or reproductive loss and decreases significantly over time for most but not all women and men. Women generally report more PTS or PTSD symptoms but clinical levels of distress are also reported for men.

Research has generally demonstrated that PTS or PTSD after TOP and reproductive losses are complex and a variety of factors play an influencing role. Studies which have investigated the impact of sociodemographic characteristics (TOP and miscarriage studies) and the experience of other previous traumas on PTS and PTSD have found that demographic factors such as maternal age, gestational age, lower education, and a history of previous physical or sexual trauma are significant risk factors for the development of PTS or PTSD after loss. Prior history of mental health problems and current depression, anxiety, and perinatal grief are also risk factors, confirming previous research [100], although it is not clear if the mental health or the known lack of health seeking behaviour is responsible for the reproductive loss [101]. Time has generally been found to be the most influential protective factor in reducing levels of PTS/PTSD. The evidence for the effectiveness of "individual" psychological therapy is mixed and generally suggest therapy is ineffective at reducing PTS or PTSD anymore than time does by itself. The quality of relationship between the couple has also been found to act as a protective factor, as is found more generally in research reporting coping with reproductive disorders [3].

The quality of studies included in the review was generally good, reaching average scores of 7/9, but the samples are often small, select, and nonrepresentative. Most studies report data for one year after TOP or loss and no inferences can be drawn about the long term consequences. This is a serious limitation because the time since the loss occurred is an important factor that influences PTS and PTSD. Further, most of the studies included did not control for pre-TOP or prereproductive loss mental health in their statistical analyses. This is potentially another significant limitation of existing research because a recent Danish population based cohort study found evidence that the incidence of pre-TOP psychiatric contacts up to 9 months preabortion (14.6\%) was similar to the incidence at 12 months post-TOP (15.2\%) among the large cohort of girls and women included in the analysis [102]. The lack of research on perinatal loss, stillbirth, and neonatal death is also of concern because a longer gestation predicts an increasing likelihood of PTS or PTSD. Evidence of PTS and reproductive loss of men, nonwhite, single women, adolescent girls, and women past the age of natural childbearing is meagre and nonexistent on failure of infertility treatment needing further attention. Finally, most of the studies that have examined TOP have come from countries that permit nonmedical TOP. Restrictive TOP laws are not associated with lower TOP rates, indeed the opposite appears to be true $[13,14]$. Therefore, the findings from this review cannot easily be transferred to those countries where TOP is illegally practiced, particularly where unsafe TOP's are carried out.

To sum, this systematic review investigated PTS/PTSD after TOP and reproductive loss. The prevalence of PTS was greater than PTSD and both decreased over time. However, the more advanced the pregnancy is, the more PTS and 
PTSD are likely to be reported. Women generally report more PTS/PTSD but men also report clinical rates of PTS/PTSD. Time since TOP and loss, demographic characteristics and psychosocial factors influence the development and maintenance of PTS and PTSD after TOP and reproductive loss.

\section{Appendix}

See Tables 1, 2, 3, and 4.

\section{Conflict of Interests}

There are no competing interests.

\section{Funding}

Viltè Daugirdaitè received an ERASMUS Internship scholarship.

\section{References}

[1] O. B. A. van den Akker, "The psychological and social consequences of miscarriage," Expert Review of Obstetrics and Gynecology, vol. 6, no. 3, pp. 295-304, 2011.

[2] F. Zegers-Hochschild, G. D. Adamson, J. de Mouzon et al., "International Committee for Monitoring Assisted Reproductive Technology (ICMART) and the World Health Organization (WHO) revised glossary of ART terminology, 2009," Fertility and Sterility, vol. 92, no. 5, pp. 1520-1524, 2009.

[3] O. B. A. van den Akker, Reproductive Health Psychology, WileyBlackwell, 2012.

[4] A. L. Greil, "Infertility and psychological distress: a critical review of the literature," Social Science and Medicine, vol. 45, no. 11, pp. 1679-1704, 1997.

[5] B. D. Peterson, M. Pirritano, U. Christensen, J. Boivin, J. Block, and L. Schmidt, "The longitudinal impact of partner coping in couples following 5 years of unsuccessful fertility treatments," Human Reproduction, vol. 24, no. 7, pp. 1656-1664, 2009.

[6] J. R. W. Fisher, K. Hammarberg, and G. H. W. Baker, "Antenatal mood and fetal attachment after assisted conception," Fertility and Sterility, vol. 89, no. 5, pp. 1103-1112, 2008.

[7] W. Bandenhorst and P. Hughes, "Psychological aspects of perinatal loss," Best Practice \& Research Clinical Obstetrics \& Gynaecology, vol. 21, pp. 249-259, 2007.

[8] S. M. Bennett, B. S. Lee, B. T. Litz, and S. Maguen, "The scope and impact of perinatal loss: current status and future directions," Professional Psychology: Research and Practice, vol. 36, no. 2, pp. 180-187, 2005.

[9] P. A. Geller, D. Kerns, and C. M. Klier, "Anxiety following miscarriage and the subsequent pregnancy: a review of the literature and future directions," Journal of Psychosomatic Research, vol. 56, no. 1, pp. 35-45, 2004.

[10] D. A. Bagarozzi, "Identification, assessment and treatment of women suffering from post traumatic stress after abortion," Journal of Family Psychotherapy, vol. 5, no. 3, pp. 25-54, 1994.

[11] J. Condon, "Women's mental health: a 'wish-list' for the DSM V," Archives of Women's Mental Health, vol. 13, no. 1, pp. 5-10, 2010.

[12] S. Iles, "The loss of early pregnancy," Bailliere's Clinical Obstetrics and Gynaecology, vol. 3, no. 4, pp. 769-790, 1989.
[13] G. Sedgh, S. Singh, I. H. Shah, E. Åhman, S. K. Henshaw, and A. Bankole, "Induced abortion: incidence and trends worldwide from 1995 to 2008," The Lancet, vol. 379, no. 9816, pp. 625-632, 2012.

[14] World Health Organisation (WHO), "Facts on induced abortion worldwide," April 2014, http://www.guttmacher.org/pubs/ fb_IAW.html.

[15] N. F. Russo and K. L. Zierk, "Abortion, childbearing, and women's well-being," Professional Psychology: Research and Practice, vol. 23, no. 4, pp. 269-280, 1992.

[16] S. M. Stanford-Rue, Will I Cry Tomorrow? Healing Post-Abortion Trauma, Fleming H. Revell, 1999.

[17] B. Major, M. Appelbaum, L. Beckman, M. A. Dutton, N. F. Russo, and C. West, "Abortion and mental health: evaluating the evidence," American Psychologist, vol. 64, no. 9, pp. 863-890, 2009.

[18] J. Astbury, "Overview of key issues," in Mental Health Aspects of Women's Reproductive Health. A Global Review of Literature, pp. 1-7, World Health Organization, 2009, http://whqlibdoc.who .int/publications/2009/9789241563567_eng.pdf.

[19] D. Carter, S. Misri, and L. Tomfohr, "Psychologic aspects of early pregnancy loss," Clinical Obstetrics and Gynecology, vol. 50, no. 1, pp. 154-165, 2007.

[20] C. Lee and P. Slade, "Miscarriage as a traumatic event: a review of the literature and new implications for intervention," Journal of Psychosomatic Research, vol. 40, no. 3, pp. 235-244, 1996.

[21] A. Horsch, "Post-traumatic stress disorder following childbirth and pregnancy loss," in Clinical Psychology in Practice, H. Beinart, P. Kennedy, and S. Llewelyn, Eds., pp. 274-287, Blackwell Publishing, West Sussex, UK, 2009.

[22] C. T. Coyle, P. K. Coleman, and V. M. Rue, "Inadequate preabortion counseling and decision conflict as predictors of subsequent relationship difficulties and psychological stress in men and women," Traumatology, vol. 16, no. 1, pp. 16-30, 2010.

[23] B. Major, C. Cozzarelli, M. L. Cooper et al., "Psychological responses of women after first-trimester abortion," Archives of General Psychiatry, vol. 57, no. 8, pp. 777-784, 2000.

[24] D. Moher, A. Liberati, J. Tetzlaff, and D. Altman, "Preferred reporting items for systematic reviews and meta-analyses: the PRISMA statement," Journal of Clinical Epidemiology, vol. 62, pp. 1006-1012, 2009.

[25] M. J. Horowitz, Stress Response Syndromes, Jason Aronson, Northvale, NJ, USA, 2001.

[26] American Psychiatric Association, Diagnostic and Statistical Manual of Mental Disorders, American Psychiatric Press, Washington, DC, USA, 5th edition, 2013, http://www.dsm5.org/Pages/ Default.aspx.

[27] J. P. T. Higgins and S. Green, Cochrane Handbook for Systematic Reviews of Interventions, 2011, http://handbook.cochrane.org/.

[28] J. M. Green, J. Hewison, H. L. Bekker, L. D. Bryant, and H. S. Cuckle, "Psychosocial aspects of genetic screening of pregnant women and newborns: a systematic review," Health Technology Assessment, vol. 8, no. 33, pp. 1-128, 2004.

[29] D. S. Armstrong, "Perinatal loss and parental distress after the birth of a healthy infant," Advances in Neonatal Care, vol. 7, no. 4, pp. 200-206, 2007.

[30] A. N. Broen, T. Moum, A. S. Bödtker, and Ö. Ekeberg, "Psychological impact on women of miscarriage versus induced abortion: a 2-year follow-up study," Psychosomatic Medicine, vol. 66, no. 2, pp. 265-271, 2004. 
[31] A. N. Broen, T. Moum, A. S. Bödtker, and Ö. Ekeberg, "Reasons for induced abortion and their relation to women's emotional distress: a prospective, two-year follow-up study," General Hospital Psychiatry, vol. 27, no. 1, pp. 36-43, 2005.

[32] P. K. Coleman, C. T. Coyle, and V. M. Rue, "Late-term elective abortion and susceptibility to posttraumatic stress symptoms," Journal of Pregnancy, vol. 2010, Article ID 130519, 10 pages, 2010.

[33] I. M. Engelhard, M. A. van den Hout, and A. Arntz, "Posttraumatic stress disorder after pregnancy loss," General Hospital Psychiatry, vol. 23, no. 2, pp. 62-66, 2001.

[34] I. M. Engelhard, M. A. van den Hout, and M. Kindt, "The relationship between neuroticism, pre-traumatic stress, and posttraumatic stress: a prospective study," Personality and Individual Differences, vol. 35, no. 2, pp. 381-388, 2003.

[35] I. M. Engelhard, M. A. van den Hout, and J. W. S. Vlaeyen, "The sense of coherence in early pregnancy and crisis support and posttraumatic stress after pregnancy loss: a prospective study," Behavioral Medicine, vol. 29, no. 2, pp. 80-84, 2003.

[36] I. M. Engelhard, M. A. van den Hout, and E. G. W. Schouten, "Neuroticism and low educational level predict the risk of posttraumatic stress disorder in women after miscarriage or stillbirth," General Hospital Psychiatry, vol. 28, no. 5, pp. 414417, 2006.

[37] M. A. van den Hout and I. M. Engelhard, "Pretrauma neuroticism, negative appraisals of intrusions, and severity of PTSD symptoms," Journal of Psychopathology and Behavioral Assessment, vol. 26, no. 3, pp. 181-183, 2004.

[38] J. A. M. Hunfeld, J. W. Wladimiroff, F. Verhage, and J. Passchier, "Previous stress and acute psychological defence as predictors of perinatal grief-an exploratory study," Social Science and Medicine, vol. 40, no. 6, pp. 829-835, 1995.

[39] J. A. M. Hunfeld, J. W. Wladimiroff, and J. Passchier, "Prediction and course of grief four years after perinatal loss due to congenital anomalies: a follow-up study," British Journal of Medical Psychology, vol. 70, no. 1, pp. 85-91, 1997.

[40] J. A. M. Hunfeld, J. W. Wladimiroff, and J. Passchier, "The grief of late pregnancy loss," Patient Education and Counseling, vol. 31, no. 1, pp. 57-64, 1997.

[41] A. Kersting, M. Dorsch, C. Kreulich et al., "Trauma and grief 27 years after termination of pregnancy because of fetal anomalies-a pilot study," Journal of Psychosomatic Obstetrics and Gynecology, vol. 26, no. 1, pp. 9-14, 2005.

[42] A. Kersting, K. Kroker, J. Steinhard et al., "Complicated grief after traumatic loss: a 14-month follow up study," European Archives of Psychiatry and Clinical Neuroscience, vol. 257, no. 8, pp. 437-443, 2007.

[43] M. J. Korenromp, G. C. M. L. Page-Christiaens, J. van den Bout et al., "Psychological consequences of termination of pregnancy for fetal anomaly: similarities and differences between partners," Prenatal Diagnosis, vol. 25, no. 13, pp. 1226-1233, 2005.

[44] M. J. Korenromp, G. C. M. L. Page-Christiaens, J. van den Bout, E. J. H. Mulder, and G. H. A. Visser, "Adjustment to termination of pregnancy for fetal anomaly: a longitudinal study in women at 4, 8, and 16 months," American Journal of Obstetrics and Gynecology, vol. 201, no. 2, pp. 160.el-160.e7, 2009.

[45] B. Major and R. H. Gramzow, "Abortion as stigma: cognitive and emotional implications of concealment," Journal of Personality and Social Psychology, vol. 77, no. 4, pp. 735-745, 1999.

[46] J. S. Seng, L. K. Low, M. Sperlich, D. L. Ronis, and I. Liberzon, "Prevalence, trauma history, and risk for posttraumatic stress disorder among nulliparous women in maternity care," Obstetrics and Gynecology, vol. 114, no. 4, pp. 839-847, 2009.
[47] A. Speckhard and N. Mufel, "Universal responses to abortion? Attachment, trauma, and grief responses in women following abortion," The Journal of Prenatal and Perinatal Psychology and Health, vol. 18, pp. 3-7, 2003.

[48] P. Turton, W. Badenhorst, P. Hughes, J. Ward, S. Riches, and S. White, "Psychological impact of stillbirth on fathers in the subsequent pregnancy and puerperium," British Journal of Psychiatry, vol. 188, pp. 165-172, 2006.

[49] P. Turton, C. Evans, and P. Hughes, "Long-term psychosocial sequelae of stillbirth. Phase II of a nested case-control cohort study," Archives of Women's Mental Health, vol. 12, no. 1, pp. 3541, 2009.

[50] P. Turton, P. Hughes, C. D. H. Evans, and D. Fainman, "Incidence, correlates and predictors of post-traumatic stress disorder in the pregnancy after stillbirth," British Journal of Psychiatry, vol. 178, pp. 556-560, 2001.

[51] P. Turton, P. Hughes, P. Fonagy, and D. Fainman, "An investigation into the possible overlap between PTSD and unresolved responses following stillbirth: an absence of linkage with only unresolved status predicting infant disorganization," Attachment and Human Development, vol. 6, no. 3, pp. 241-253, 2004.

[52] D. S. Armstrong, M. H. Hutti, and J. Myers, "The influence of prior perinatal loss on parents' psychological distress after the birth of a subsequent healthy infant," Journal of Obstetric, Gynecologic, and Neonatal Nursing, vol. 38, no. 6, pp. 654-666, 2009.

[53] A. N. Broen, T. Moum, A. S. Bødtker, and Ø. Ekeberg, “The course of mental health after miscarriage and induced abortion: a longitudinal, five-year follow-up study," BMC Medicine, vol. 3, article 18, 2005.

[54] I. M. Engelhard, M. A. van den Hout, M. Kindt, A. Arntz, and E. Schouten, "Peritraumatic dissociation and posttraumatic stress after pregnancy loss: a prospective study," Behaviour Research and Therapy, vol. 41, no. 1, pp. 67-78, 2003.

[55] L. Hamama, S. A. M. Rauch, M. Sperlich, E. Defever, and J. S. Seng, "Previous experience of spontaneous or elective abortion and risk for posttraumatic stress and depression during subsequent pregnancy," Depression and Anxiety, vol. 27, no. 8, pp. 699-707, 2010.

[56] P. Hughes, P. Turton, E. Hopper, and C. D. H. Evans, "Assessment of guidelines for good practice in psychosocial care of mothers after stillbirth: a cohort study," The Lancet, vol. 360, no. 9327, pp. 114-118, 2002.

[57] J. A. M. Hunfeld, J. W. Wladimiroff, J. Passchier, M. Uniken Venema-Van Uden, P. G. Frets, and F. Verhage, "Emotional reactions in women in late pregnancy (24 weeks or longer) following the ultrasound diagnosis of a severe or lethal fetal malformation," Prenatal Diagnosis, vol. 13, no. 7, pp. 603-612, 1993.

[58] A. Kersting, K. Kroker, J. Steinhard et al., "Psychological impact on women after second and third trimester termination of pregnancy due to fetal anomalies versus women after preterm birth-a 14-month follow up study," Archives of Women's Mental Health, vol. 12, no. 4, pp. 193-201, 2009.

[59] M. J. Korenromp, G. C. M. L. Christiaens, J. Van Den Bout et al., "Long-term psychological consequences of pregnancy termination for fetal abnormality: a cross-sectional study," Prenatal Diagnosis, vol. 25, no. 3, pp. 253-260, 2005.

[60] M. J. Korenromp, G. C. M. L. Page-Christiaens, J. van den Bout et al., "A prospective study on parental coping 4 months after termination of pregnancy for fetal anomalies," Prenatal Diagnosis, vol. 27, no. 8, pp. 709-716, 2007. 
[61] N. Mufel, A. Speckhard, and S. Sivuha, "Predictors of posttraumatic stress disorder following abortion in a former Soviet Union country," The Journal of Prenatal and Perinatal Psychology and Health, vol. 17, pp. 41-61, 2002.

[62] P. K. Coleman, C. T. Coyle, M. Shuping, and V. M. Rue, "Induced abortion and anxiety, mood, and substance abuse disorders: isolating the effects of abortion in the national comorbidity survey," Journal of Psychiatric Research, vol. 43, no. 8, pp. 770776, 2009.

[63] J. R. Steinberg and L. B. Finer, "Examining the association of abortion history and current mental health: a reanalysis of the National Comorbidity Survey using a common-risk-factors model," Social Science and Medicine, vol. 72, no. 1, pp. 72-82, 2011.

[64] S. Allanson, "Abortion decision and ambivalence: insights via an abortion decision balance sheet," Clinical Psychologist, vol. 11, no. 2, pp. 50-60, 2007.

[65] L. Cohen and S. Roth, "Coping with abortion," Journal of Human Stress, vol. 10, no. 3, pp. 140-145, 1984.

[66] A. A. P. van Emmerik, J. H. Kamphuis, and P. M. G. Emmelkamp, "Prevalence and prediction of re-experiencing and avoidance after elective surgical abortion: a prospective study," Clinical Psychology \& Psychotherapy, vol. 15, no. 6, pp. 378-385, 2008.

[67] A. Hemmerling, F. Siedentopf, and H. Kentenich, "Emotional impact and acceptability of medical abortion with mifepristone: a German experience," Journal of Psychosomatic Obstetrics and Gynecology, vol. 26, no. 1, pp. 23-31, 2005.

[68] T. Kelly, J. Suddes, D. Howel, J. Hewison, and S. Robson, "Comparing medical versus surgical termination of pregnancy at 13-20weeks of gestation: a randomised controlled trial," British Journal of Obstetrics and Gynaecology, vol. 117, no. 12, pp. 1512-1520, 2010.

[69] S. D. Layer, C. Roberts, K. Wild, and J. Walters, "Postabortion grief: evaluating the possible efficacy of a spiritual group intervention," Research on Social Work Practice, vol. 14, no. 5, pp. 344-350, 2004.

[70] L. M. Pope, N. E. Adler, and J. M. Tschann, "Postabortion psychological adjustment: are minors at increased risk?" Journal of Adolescent Health, vol. 29, no. 1, pp. 2-11, 2001.

[71] C. Rousset, C. Brulfert, N. Séjourné, N. Goutaudier, and H. Chabrol, "Posttraumatic stress disorder and psychological distress following medical and surgical abortion," Journal of Reproductive and Infant Psychology, vol. 29, no. 5, pp. 506-517, 2012.

[72] V. M. Rue, P. K. Coleman, J. J. Rue, and D. C. Reardon, "Induced abortion and traumatic stress: a preliminary comparison of American and Russian women," Medical Science Monitor, vol. 10, no. 10, pp. SR5-SR16, 2004.

[73] P. Slade, S. Heke, J. Fletcher, and P. Stewart, "A comparison of medical and surgical termination of pregnancy choice, psychological consequences and satisfaction with care," British Journal of Obstetrics and Gynaecology, vol. 105, no. 12, pp. 12881295, 1998.

[74] S. Suliman, T. Ericksen, P. Labuschgne, R. de Wit, D. J. Stein, and S. Seedat, "Comparison of pain, cortisol levels, and psychological distress in women undergoing surgical termination of pregnancy under local anaesthesia versus intravenous sedation," BMC Psychiatry, vol. 7, article 24, 2007.

[75] J. Trybulski, "Women and abortion: the past reaches into the present," Journal of Advanced Nursing, vol. 54, no. 6, pp. 683690, 2006.
[76] V. J. Walters and D. A. Oakley, "Hypnosis in post-abortion distress: an experimental case study," Contemporary Hypnosis, vol. 19, no. 2, pp. 85-99, 2002.

[77] C. Canário, B. Figueiredo, and M. Ricou, "Women and men’s psychological adjustment after abortion: a six months prospective pilot study," Journal of Reproductive and Infant Psychology, vol. 29, no. 3, pp. 262-275, 2011.

[78] F. S. Cowchock, S. E. Ellestad, K. G. Meador, H. G. Koenig, E. G. Hooten, and G. K. Swamy, "Religiosity is an important part of coping with grief in pregnancy after a traumatic second trimester loss," Journal of Religion and Health, vol. 50, no. 4, pp. 901-910, 2011.

[79] V. Davies, J. Gledhill, A. McFadyen, B. Whitlow, and D. Economides, "Psychological outcome in women undergoing termination of pregnancy for ultrasound-detected fetal anomaly in the first and second trimesters: a pilot study," Ultrasound in Obstetrics and Gynecology, vol. 25, no. 4, pp. 389-392, 2005.

[80] R. Fernandez, D. Harris, and A. Leschied, "Understanding grief following pregnancy loss: a retrospective analysis regarding women's coping responses," Illness Crisis and Loss, vol. 19, no. 2, pp. 143-163, 2011.

[81] J. Kroth, M. Garcia, M. Hallgren, E. LeGrue, M. Ross, and J. Scalise, "Perinatal loss, trauma, and dream reports," Psychological Reports, vol. 94, no. 3, pp. 877-882, 2004.

[82] K. A. Salvesen, L. Øyen, N. Schmidt, U. F. Malt, and S. H. Eik-Nes, "Comparison of long-term psychological responses of women after pregnancy termination due to fetal anomalies and after perinatal loss," Ultrasound in Obstetrics and Gynecology, vol. 9, no. 2, pp. 80-85, 1997.

[83] L. Alderman, J. Chisholm, F. Denmark, and S. Salbod, "Bereavement and stress of a miscarriage: as it affects the couple," Omega, vol. 37, no. 4, pp. 317-327, 1998.

[84] S. V. Bowles, R. S. Bernard, T. Epperly et al., "Traumatic stress disorders following first-trimester spontaneous abortion: a pilot study of patient characteristics associated with these disorders," Journal of Family Practice, vol. 55, no. 11, pp. 969-973, 2006.

[85] M. P. Johnson and J. E. Puddifoot, "The grief response in the partners of women who miscarry," Psychology and Psychotherapy: Theory, Research and Practice, vol. 69, no. 4, pp. 313-327, 1996.

[86] C. Lee, P. Slade, and V. Lygo, "The influence of psychological debriefing on emotional adaptation in women following early miscarriage: a preliminary study," The British Journal of Medical Psychology, vol. 69, no. 1, pp. 47-58, 1996.

[87] E. Rowsell, G. Jongman, M. Kilby, R. Kirchmeier, and J. Orford, "The psychological impact of recurrent miscarriage, and the role of counselling at a pre-pregnancy counselling clinic," Journal of Reproductive and Infant Psychology, vol. 19, no. 1, pp. 3345, 2001.

[88] N. Séjourné, S. Callahan, and H. Chabrol, "The utility of a psychological intervention for coping with spontaneous abortion," Journal of Reproductive and Infant Psychology, vol. 28, no. 3, pp. 287-296, 2010.

[89] F. Serrano and M. L. Lima, "Recurrent miscarriage: psychological and relational consequences for couples," Psychology and Psychotherapy: Theory, Research and Practice, vol. 79, no. 4, pp. 585-594, 2006.

[90] A. K.-H. Sham, M. G.-C. Yiu, and W. Y.-B. Ho, "Psychiatric morbidity following miscarriage in Hong Kong," General Hospital Psychiatry, vol. 32, no. 3, pp. 284-293, 2010.

[91] T. M. Walker and K. M. Davidson, "A preliminary investigation of psychological distress following surgical management of 
early pregnancy loss detected at initial ultrasound scanning: a trauma perspective," Journal of Reproductive and Infant Psychology, vol. 19, no. 1, pp. 7-16, 2001.

[92] D. S. Armstrong, "Impact of prior perinatal loss on subsequent pregnancies," JOGNN-Journal of Obstetric, Gynecologic, and Neonatal Nursing, vol. 33, no. 6, pp. 765-773, 2004.

[93] A. Forray, L. C. Mayes, U. Magriples, and C. N. Epperson, "Prevalence of post-traumatic stress disorder in pregnant women with prior pregnancy complications," Journal of Maternal-Fetal and Neonatal Medicine, vol. 22, no. 6, pp. 522527, 2009.

[94] L. Jind, "Do traumatic events influence cognitive schemata?" Scandinavian Journal of Psychology, vol. 42, no. 2, pp. 113-120, 2001.

[95] L. Jind, "Parents' adjustment to late abortion, stillbirth or infant death: the role of causal attributions," Scandinavian Journal of Psychology, vol. 44, no. 4, pp. 383-394, 2003.

[96] J. O'Leary, "The trauma of ultrasound during a pregnancy following perinatal loss," Journal of Loss and Trauma, vol. 10, no. 2, pp. 183-204, 2005.

[97] M. H. Hutti, D. S. Armstrong, and J. Myers, "Healthcare utilization in the pregnancy following a perinatal loss," $M C N$ The American Journal of Maternal/Child Nursing, vol. 36, no. 2, pp. 104-111, 2011.

[98] J. Cacciatore, "Effects of support groups on post traumatic stress responses in women experiencing stillbirth," Omega: Journal of Death and Dying, vol. 55, no. 1, pp. 71-90, 2007.

[99] T. H. Uren and C. A. Wastell, "Attachment and meaning-making in perinatal bereavement," Death Studies, vol. 26, no. 4, pp. 279308, 2002.

[100] K. J. Gold and S. M. Marcus, "The effect of maternal mental illness on pregnancy outcomes," Expert Review of Obstetrics and Gynecology, vol. 3, no. 3, pp. 391-401, 2008.

[101] L. Bonari, N. Pinto, E. Ahn, A. Einarson, M. Steiner, and G. Koren, "Perinatal risks of untreated depression during pregnancy," Canadian Journal of Psychiatry, vol. 49, no. 11, pp. 726735, 2004.

[102] T. Munk-Olsen, T. M. Laursen, C. B. Pedersen, Ø. Lidegaard, and P. B. Mortensen, "Induced first-trimester abortion and risk of mental disorder," The New England Journal of Medicine, vol. 364, no. 4, pp. 332-339, 2011. 


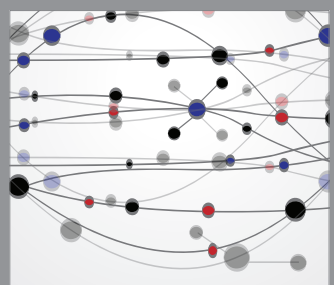

The Scientific World Journal
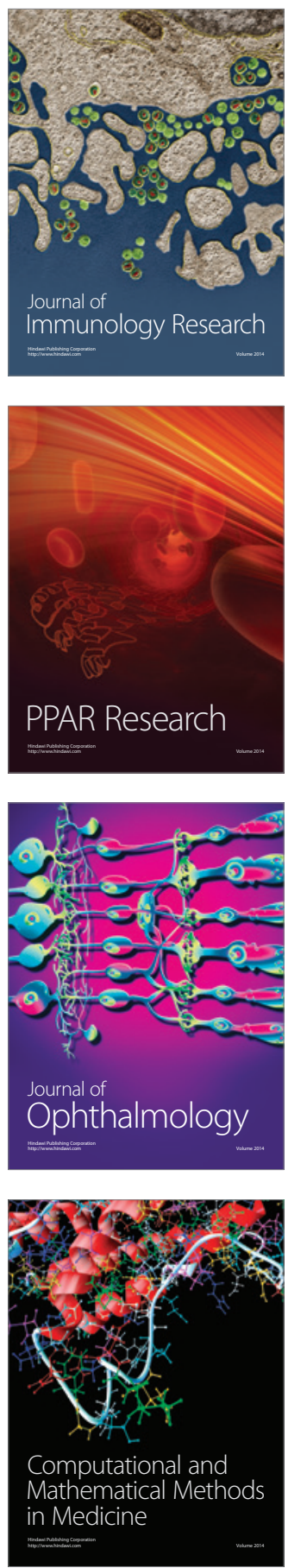

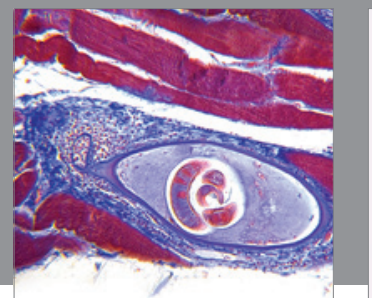

Gastroenterology

Research and Practice
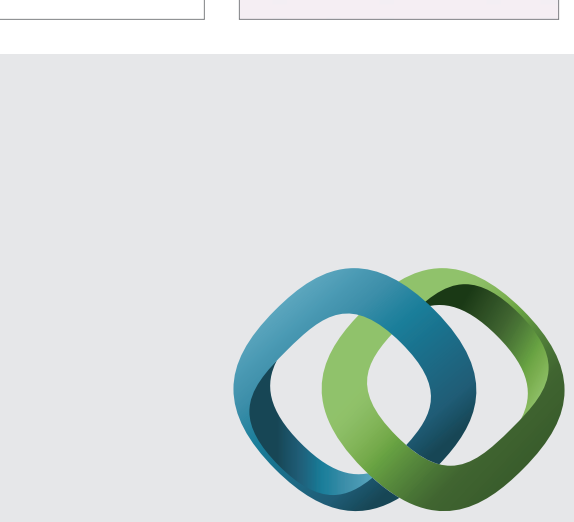

\section{Hindawi}

Submit your manuscripts at

http://www.hindawi.com
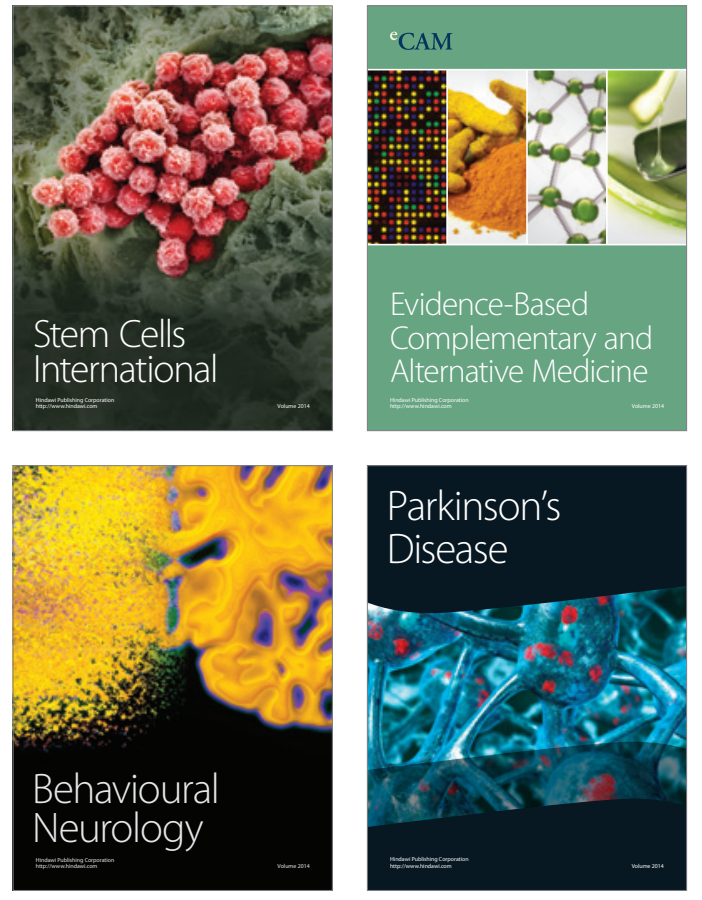
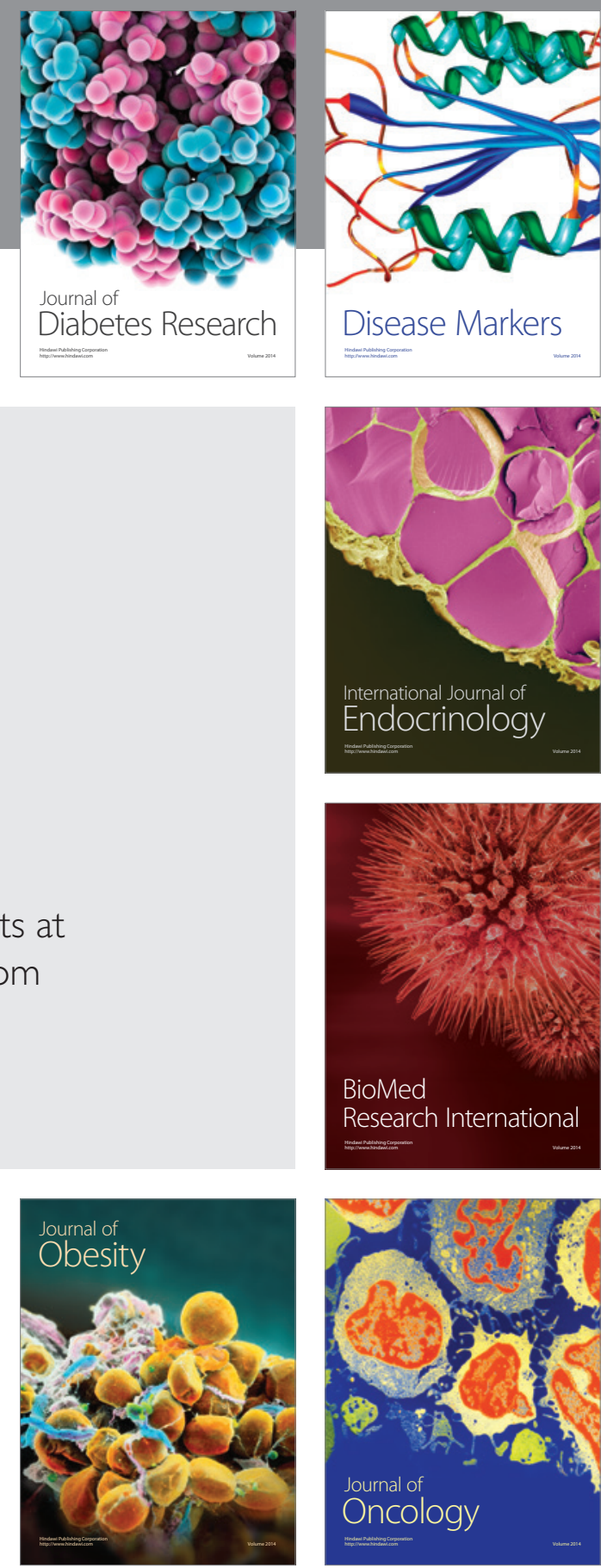

Disease Markers
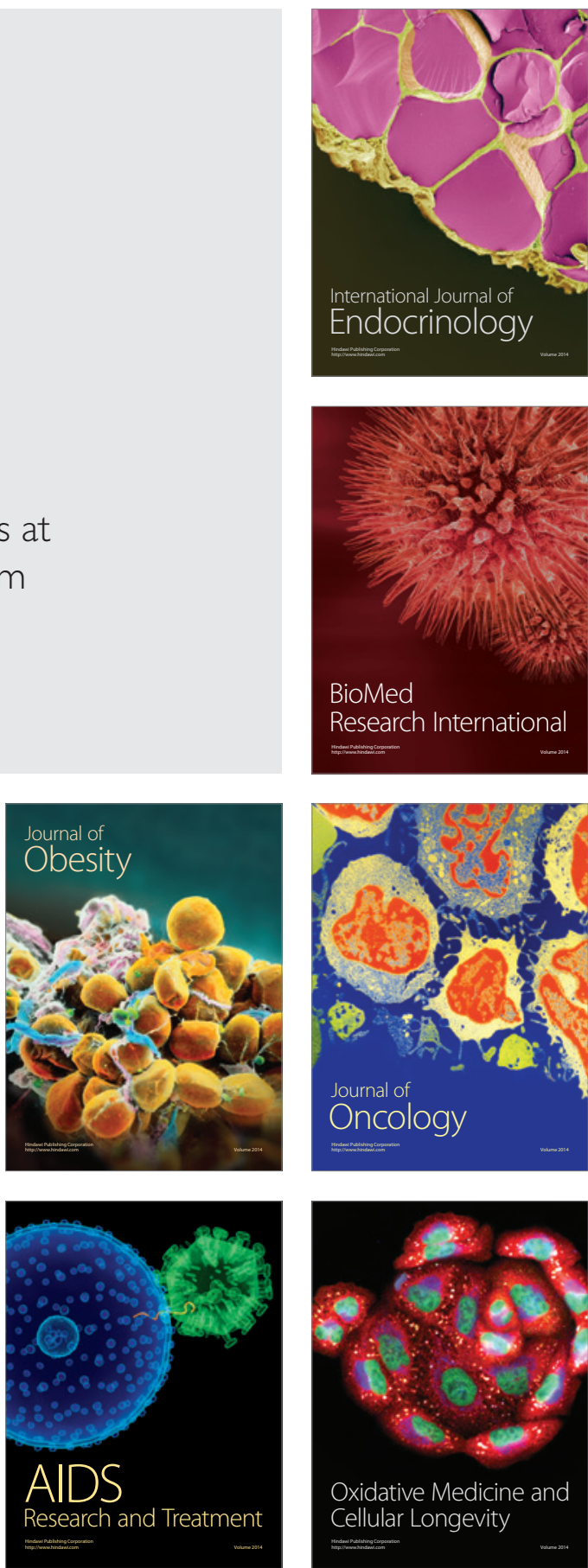